\title{
Image of the month: A giant unruptured anterior communicating artery aneurysm presenting with seizures
}

Authors: Dylan ] Mac Lochlainn, ${ }^{A}$ Vasileios Sotiropoulos ${ }^{B}$ and Breffni C Keegan ${ }^{C}$

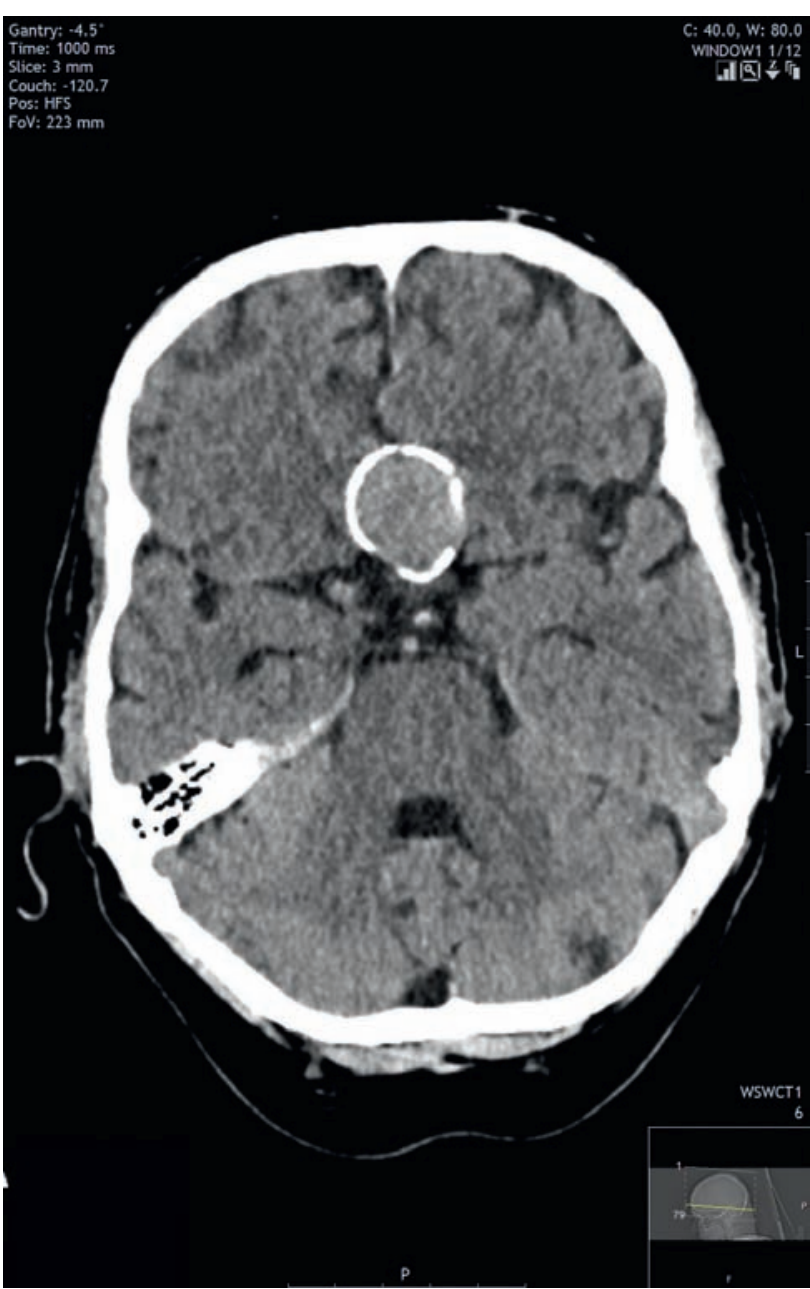

Fig 1. Computed tomography showing a soft tissue mass with peripheral calcifications

A 74-year-old man presented following a presumed first seizure. His wife awoke to find him unresponsive, grunting and foaming at the mouth. He was responding appropriately when the ambulance

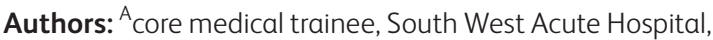
Enniskillen, UK; ${ }^{B}$ consultant radiologist, South West Acute Hospital, Enniskillen, UK; ${ }^{C}$ consultant stroke physician, South West Acute Hospital, Enniskillen, UK

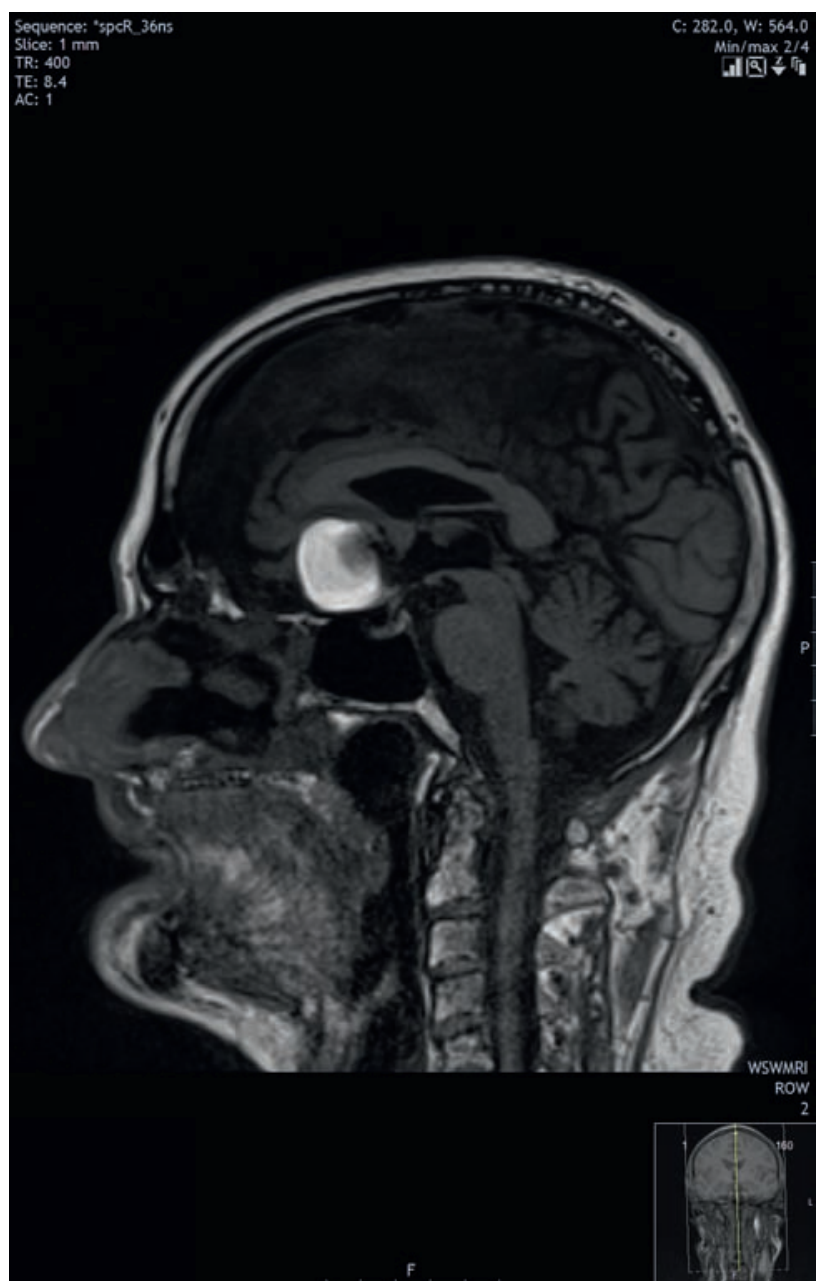

Fig 2. T1-weighted magnetic resonance image showing the thrombosed aneurysmal sac splaying the posterior optic nerves.

crew attended. There was no associated limb jerking, incontinence or tongue biting, and he denied chest pain or palpitations. A similar episode four years earlier was reported, but he had never received a formal diagnosis of epilepsy. Clinical examination was unremarkable. Admission computed tomography (CT) revealed a homogeneous soft tissue mass with calcifications superior to the pituitary fossa (Fig 1). Blood tests, including adrenocorticotropic hormone, insulin-like growth factor-1, thyroid stimulating hormone and short synacthen test, were unremarkable. Visual field testing was normal. 


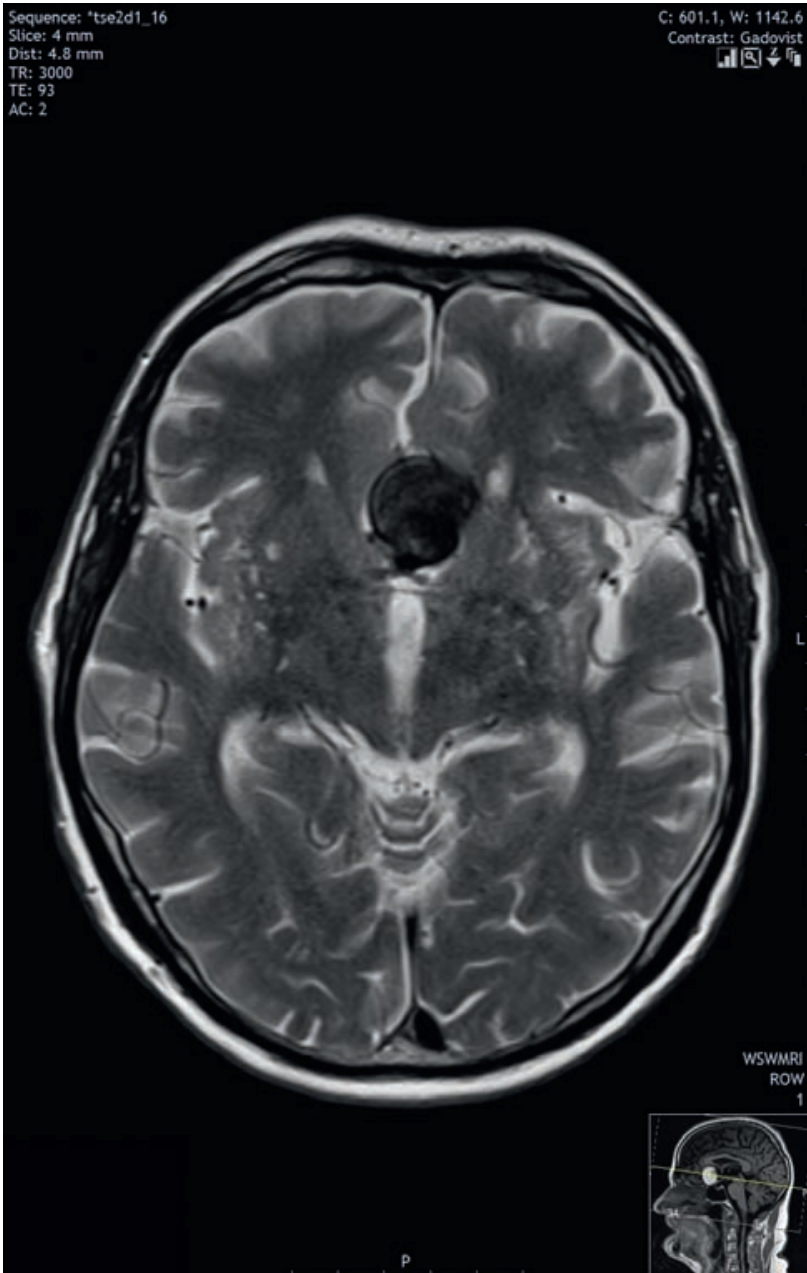

Fig 3. T2-weighted magnetic resonance image showing a hypointense thrombosed aneurysmal sac.

Magnetic resonance (MR) imaging brain and MR angiography demonstrated a large left anterior communicating artery (ACOA) saccular aneurysm. The thrombosed aneurysmal sac displayed high signal intensity on T1-weighted images with splaying of the posterior optic nerves (Fig 2), and appeared hypointense on the T2-weighted sequences (Fig 3). On 3D time-of-flight MR angiogram (Fig 4), flow was identified within the neck of the aneurysm. There was no evidence of associated bleeding or additional aneurysms, and pituitary fossa was normal with no adenoma.

He underwent review by the regional neurosurgical team. No operative intervention was advised, and interval imaging involving CT angiography was recommended.

Several days later, he re-presented following a witnessed tonicclonic seizure. CT angiogram on this admission noted no interval change. Antiepileptic medication was introduced at this point. At outpatient review 1 month later, he reported no further seizures.

Giant intracranial aneurysms are defined as aneurysms exceeding $25 \mathrm{~mm}$ in diameter and comprise approximately 5\% of all intracranial aneurysms. Unruptured intracranial aneurysms are a rare but recognised cause of epilepsy. Reported cases have

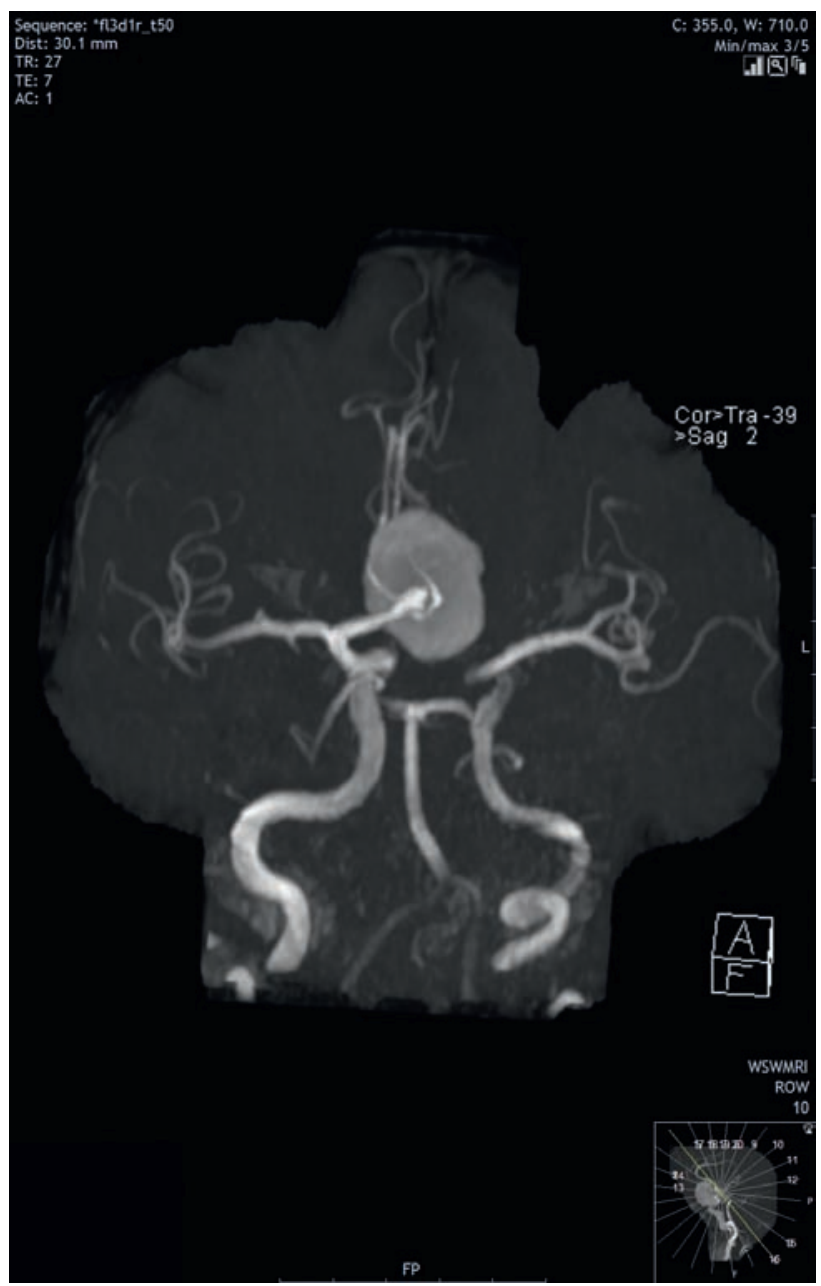

Fig 4. Magnetic resonance angiogram showing blood flow within the neck of the aneurysm.

predominantly been associated with middle cerebral artery aneurysms, with only rare reports involving ACoA aneurysms. ${ }^{1}$ The management of giant intracranial aneurysms can be problematic, and the optimal treatment has not been clearly established. Surgical clipping is considered to be particularly high risk for giant aneurysms, but a range of endovascular techniques exist as potential alternatives where intervention is being considered. ${ }^{2}$ Overall, the prognosis for giant aneurysms is often poor. ${ }^{2}$.

\section{References}

1 Patil A, Menon GR, Nair S. Unruptured anterior communicating artery aneurysms presenting with seizure. Asian J Neurosurg 2013;8:164.

2 Lv X, Jiang C, Li Y et al. Treatment of giant intracranial aneurysms. Interv Neuroradiology 2009;15:135-44.

Address for correspondence: Dr Breffni C Keegan, consultant stroke physician, South West Acute Hospital, Enniskillen BT74 6DN, UK.

Email: breffni.keegan@westerntrust.hscni.net 